\title{
Computational Model of Rotary Engine Thermodynamic Cycle
}

\author{
Milan Drbal ${ }^{1, *}$ \\ 1 Brno University of Technology, Faculty of Mechanical Engineering, Institute of Automotive Engineering, Technická 2896/2,61669 Brno, Czech Republic
}

\begin{abstract}
During the engine prototype design period the performance predictions are the key subject of the development. For the piston reciprocating engines a wide spectrum of the analytical approaches was developed as well as the numerical software (GT-Suite, Ricardo Wave etc.) is being used often. The increasing demand for the high-power output engines with a low displacement and weight for the UAV and marine applications, makes Wankel rotary engine a sensible option. The commercially available software for the performance prediction does not include required algorithms for the rotary engine calculation. This paper provides an approach to be used in the simulation model setup as well as the comparison of the simulation outcome with the measured data.
\end{abstract}

Keywords: rotary engine, engine performance prediction, 1D simulation.

\section{Introduction}

The main motivation for the 1D simulation software application is the reduced time to development of the engine prototype with desired performance characteristics. Said software provides relatively fast calculations of the effects of the entire engine assembly from the intake to the exhaust of the engine as well as the application of the optimization algorithm for the fine tuning of the engine parameters according to the demands of the manufacturer. As the demand of the market for the piston reciprocating engines vastly outweighs the rotary engine, said software is developed mainly for the prior engine type. The equations and the algorithms used are to be altered for the correct outcome of the simulation. The main differences that prevent the direct use of the software are as follows:

$\checkmark$ The ratio of the main shaft rotation to the 4-stroke cycles of the rotary engine is equal to 3. Single cylinder 4-stroke piston engine crankshaft rotates twice for the same quantity of cycles.

$\checkmark$ The difference of the surface to displacement ratio during the main-shaft rotation.

$\checkmark$ The difference in the heat-transfer proprieties coming from the differences in the geometric shape of the combustion chamber.

$\checkmark$ The length of the combustion chamber increases the time of the combustion process, which reduces the overall efficiency of the combustion.

$\checkmark$ The movement of the working chamber across the whole loop of the main housing influences the difference in the temperature distribution of the engine. The speed of this process also influences the speed of the flame propagation through the working camber as the leading apex seal of the rotor is constantly moving forward from the flame-front in relation to the engine operating speed.

The previous differences must be accounted for in the simulation model of the engine. This paper will discuss the methods that will be applied in creation of the virtual piston reciprocating engine used in the simulation solver algorithm. For the model preparation and simulation solving the GT-Suite software package will be presented. 


\section{Model preparation}

The initial condition in the simulation model setup must be the equity of the volume of the operating chambers in relation to the crank-shaft rotation. As the input the piston position of the virtual piston engine (VPE) in relation to the crank-shaft angle $\alpha$ is used in the algorithm the equation used for the virtual piston position:

$$
x=\frac{e^{2}\left[\pi+\left(\frac{\pi}{3}-\frac{\sqrt{3}}{4}\right) \lambda^{2}-\frac{3 \sqrt{3}}{2} \lambda \cos \left[\frac{2}{3}\left(\alpha-\frac{\pi}{2}\right)\right]\right] h_{p}-S_{4} h_{p}+V_{p}}{B}[\mathrm{~mm}]
$$

Where,

$e$ - eccentricity of the rotary mechanism [mm]

$\lambda$ - trochoid constant [-]

$\alpha$ - relative angle of the rotor [rad]

$S_{4}$ - area between the outer shell of the trochoid and

the line between 2 apexes of the rotor [mm]

$h_{\mathrm{p}}-$ rotor width [mm]

$V_{\mathrm{p}}$ - rotor hollow volume $\left[\mathrm{mm}^{3}\right]$

The bore of the VPE is taken as the diameter of the circle with equal area to the area of the rotor exposed to the working chamber.

The head area of the cylinder of the piston reciprocating engine remains constant during the engine operation, yet in the rotary engine from its principle the area changes with the main shaft rotation.

This difference is not accounted for in the algorithms for the 1D simulation solver. The virtual area of the head equivalent surfaces is therefore calculated as the weighted average with the heat flux to the head area as the weight of the calculation.

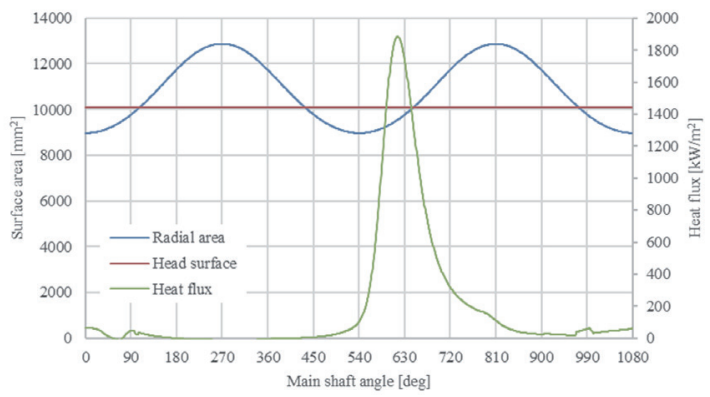

Fig. 1: Equivalent head area calculation.

The heat transfer properties are influenced by the different geometric shape of the combustion chamber, the approach used in [1] was used to determine the heat transfer coefficient in the work chamber. The [2] states that the heat transfer coefficient (HTC) calculated using the previous method is greater than the value calculated by the commercial piston 1D simulation software by 10 to $15 \%$. Taking this into the consideration, the overall HTC was increased by $15 \%$. The heat transfer from the combustion process to the surrounding work chamber walls is than calculated by the software using the surface area data from the kinematic simulation, the temperature of the work chamber walls derived from the data measured at the NKU testing facility [3] and the temperature of the working fluid inside the engine computed from the heat generation of the burned fuel using Wiebe model. The coefficients used in the Wiebe model were estimated using the available literature [4-10]. The combustion model used in the calculation takes into the account the larger length of the combustion area as well as the effect of the rotation of the working chamber in relation to the engine housing. The unburned ratio of the charge was taken as 0.025 for the first iteration of the calculation. Due to the length of the combustion chamber the overall angle of the thermal energy input from the fuel was taken as the 50 degree of the rotor rotation. The final Wiebe curve:

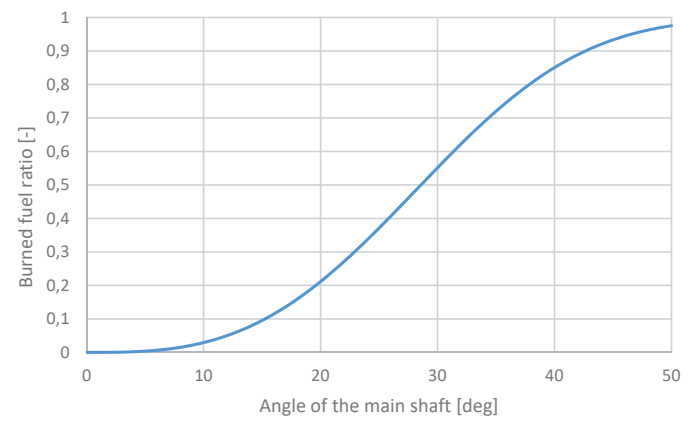

Fig. 2: The heat release model used in the calculation.

The rotary engine of the Wankel type works with four-stroke cycle and each rotor and housing pair creates 3 working chambers. For these reasons it is advisable using the four-stroke template with 3 -cylinder configuration. To maintain the equity of the volumetric flow through the VPE and the rotary engine the ratio of the main shaft rotation to the rotation of the crankshaft of the VPE is $3 / 2$. The cylinders are connected with the piping of the 


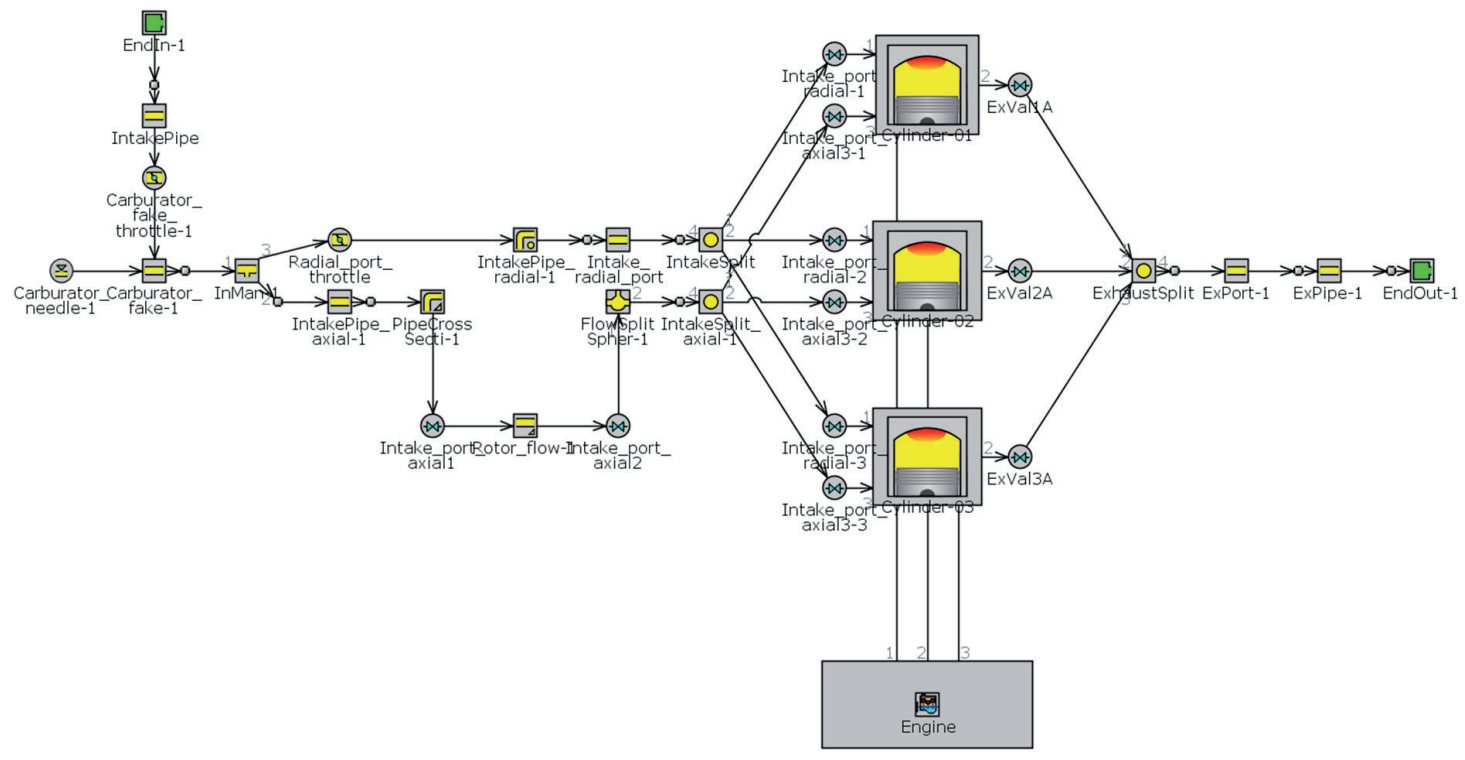

Fig. 3: Main outline of the simulation model (GT-Power).

negotiable length simulating the overflow of the exhaust and the intake during the port openings to the adjacent chambers. Both intake and the exhaust port openings were simulated with a kinematic simulation to determine the active areas of the ports in relation to the main shaft rotation. The calibration of the flow coefficient of the ports was done using the CFD approach, then further calibrated in the GT-Power software via volumetric flow measured on the test engine.

\section{Results and Discussion}

The main aspect of the simulation is the performance prediction of the designed prototype. For the verification of the model it is advisable to compare the simulated solution data to the previously measured available engine of the same concept design. For this verification the Aixro XR 50 engine was measured and tested on the bench. The correlation factor of 0.989 was achieved for the power curve characteristic. The air flow characteristics show larger difference in the lower spectrum of the engine speed. Further calibration of the ratio of the radial and axial intake port is needed.

Using the calibrated model, the first outline of the designed engine was created. Engine parameters were altered using the optimisation of the intake and exhaust parameters of the engine to

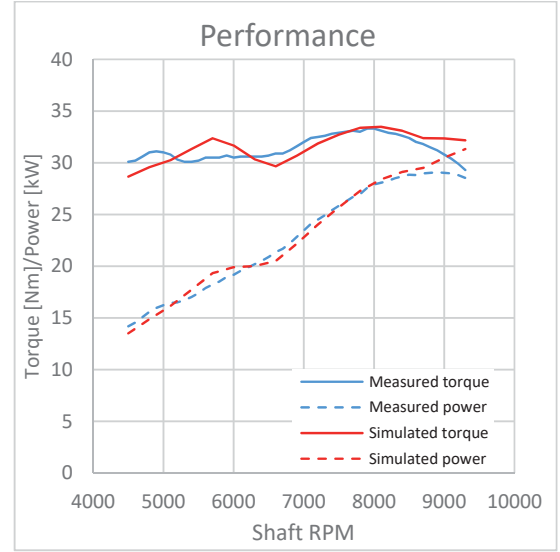

Fig. 4: The performance characteristics comparison between the simulated data and the measurement (Aixro XR 50).

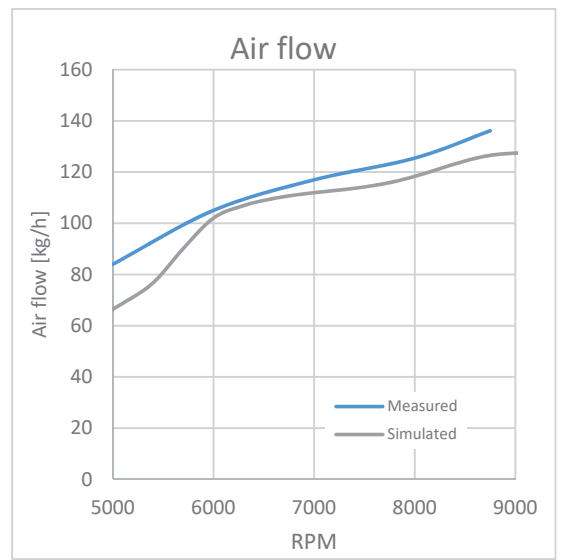

Fig. 5: The comparison of the air flow through the engine on measured data and the simulation. 
provide the desired performance. The comparison of the measured data with the predicted data from the simulation show the same trend of the torque curves, yet the absolute value of the measured torque is lower. This difference is mainly caused by the mechanical losses of the dynamometer and the uncalibrated heat release model. Further calibration using in-chamber pressure measurement is to be done.

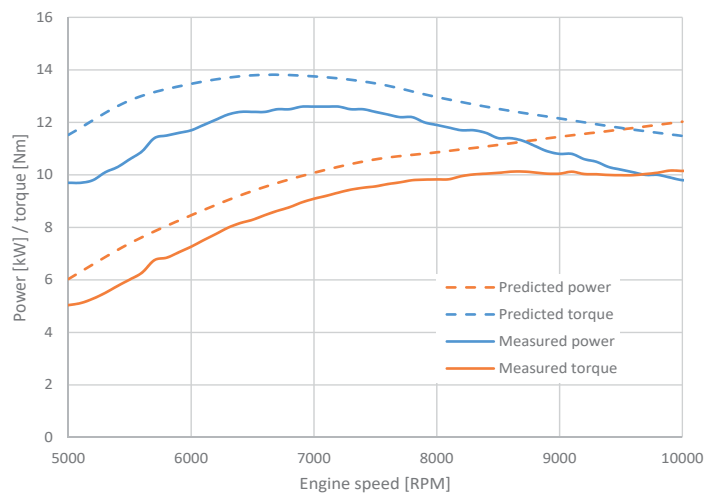

Fig. 6: The comparison of the measured and the predicted performance characteristics of the designed prototype engine.

\section{Conclusions}

The comparable low market demand to the piston reciprocating engines is the reason for the low availability of the simulation software for the rotary engines. The modification of some key parameters of the engine is needed to design a virtual piston engine used for the calculation yielding the performance results of the rotary engine. The equivalent surface and volume parameters are necessary for the calculation, paper shows the approach for the establishing the bore and piston position of the virtual piston engine for this equivalency. For the flow coefficients of the engine ports, CFD method or experimental approach might be used. The kinematic analysis of the port openings was done to create lift curves for the ports. With the outcome of the 3D simulation, the 1D simulation was calibrated to provide the comparable air flow properties. The heat transfer coefficients were calculated using the forced convection over the flat plane analogy. This calculation was than used as a weight for the calculation of the head surface average. The results of the simulation were compared to the measured performance parameters on the Aixro XR 50 engine. Utilizing the same engine concept, the performance prediction was done for the designed prototype with optimized parameters according to the previous demands. Using this approach, the time to design of the acceptable prototype was reduced significantly.

\section{Acknowledgments}

This work is an output of the internal BUT research Project Reg. No. FSI-S-17-4104.

\section{References and Notes}

[1] Bartrand, T. and Willis, E. Performance of a supercharged direct-injection stratified-charge rotary combustion engine. [online] Ntrs.nasa.gov. Available at: https://ntrs.nasa.gov/archive/nasa/casi.ntrs.nasa.gov/19900016666.pdf, 1990.

[2] Tartakovsky, L., Baibikov, V., Gutman, M., Veinblat, M. et al, Simulation of Wankel Engine Performance Using Commercial Software for Piston Engines. SAE Technical Paper 201232-0098, 2012, https://doi.org/10.4271/2012-32-0098.

[3] Norbye, J. The Wankel Engine Design, Development, Applications Philadelphia: Chilton Book Co., 1971

[4] Irion, C. and Mount, R. Stratified Charge Rotary Engine Critical Technology Enablement, Volume 1. [online] Ntrs. nasa.gov. Available at: https://ntrs.nasa.gov/search. jsp?R=19940029725, 2018.

[5] F. Handschuh, R. and Owen, A. Analysis of Apex Seal Friction Power Loss in Rotary Engines. [online] Ntrs.nasa.gov. Available at: https://ntrs.nasa.gov/archive/nasa/casi.ntrs.nasa. gov/20100036253.pdf, 2010

[6] Vilmann, C. Deformation Analysis of Rotary Combustion Engine Housings. [online] Ntrs.nasa.gov. Available at: $\quad$ https://ntrs.nasa.gov/archive/nasa/casi.ntrs.nasa. gov/19910017844.pdf, 1991.

[7] Puškár, M.; Bigoš, P.: Method For Accurate Measurements Of Detonations In Motorbike High Speed Racing Engine, Measurement 2012, Vol. 45, No. 3 (2012), P. 529-534, Issn 02632241

[8] Puškár, M.; Bigoš, P.; Puškárová, P.: Accurate Measurements Of Output Characteristics And Detonations Of Motorbike High-Speed Racing Engine And Their Optimization At Actual Atmospheric Conditions And Combusted Mixture Composition, Measurement 2012, Vol. 45, No. 5 (2012), P. 1067-1076, Issn 0263-2241

[9] Puškár, M.; Bigoš, P.: Output Performance Increase Of TwoStroke Combustion Engine With Detonation Combustion Optimization, Strojarstvo 2010: Vol. 52, No. 5 (2010), P. 577 587, Issn 0562-1887

[10] Puškár, M.; Bigoš, P. Measuring Of Acoustic Wave Influences Generated At Various Configurations Of Racing Engine Inlet And Exhaust System On Brake Mean Effective Pressure, Measurement 46 (9) (2013) 3389-3400. Issn 0263-2241. 